\title{
Influence of type 2 diabetes on muscle deoxygenation during ramp incremental cycle exercise
}

Norita Gildea

Joel Rocha

Adam McDermott

Donal O'Shea

Simon Green

Mikel Egaña

This is the accepted manuscript $(\odot 2019$, Elsevier Licensed under the Creative Commons AttributionNonCommercial-NoDerivatives 4.0 International: http://creativecommons.org/licenses/by-nc-nd/4.0/

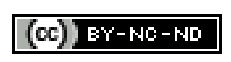

The published article is available from doi:

https://doi.org/10.1016/i.resp.2019.103258 
1

2 Influence of type 2 diabetes on muscle deoxygenation during ramp incremental cycle exercise

3

4 AUTHORS

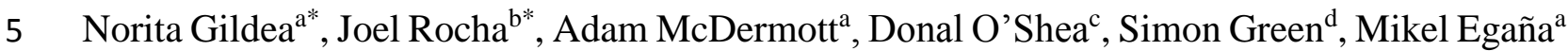

7 AFFILIATIONS \& ADDRESSES

$8 \quad{ }^{a}$ Department of Physiology, School of Medicine, Trinity College Dublin, Dublin Ireland.

$9 \quad{ }^{b}$ Division of Sport and Exercise Sciences, Abertay University, Dundee, UK.

10 'Endocrinology, St Columcille's and St Vincent's Hospitals, Dublin, Ireland.

$11{ }^{\mathrm{d}}$ School of Science and Health, Western Sydney University, Sydney, Australia.

$12 *$ N Gildea and J Rocha contributed equally to this work

13

14 CONTACT INFORMATION (corresponding author):

15 Mikel Egaña

16 Department of Physiology, School of Medicine

17 Trinity College Dublin

18 Dublin 2, Ireland.

19 E-mail: megana@tcd.ie

20

Telephone: +35318961770

21

Fax: +35316793545 


\section{ABSTRACT}

We tested the hypothesis that type 2 diabetes (T2D) alters the profile of muscle fractional oxygen $\left(\mathrm{O}_{2}\right)$ extraction (near-infrared spectroscopy) during incremental cycle exercise. Seventeen middle-aged individuals with uncomplicated T2D and 17 controls performed an upright ramp test to exhaustion. The rate of muscle deoxygenation (i.e. deoxygenated haemoglobin and myoglobin concentration, $\Delta[\mathrm{HHb}+\mathrm{Mb}])$ profiles of the vastus lateralis muscle were normalised to $100 \%$ of the response, plotted against \% power output (PO) and fitted with a double linear regression model. Peak oxygen uptake was significantly $(P<0.05)$ reduced in individuals with $\mathrm{T} 2 \mathrm{D}$. The $\% \Delta[\mathrm{HHb}+\mathrm{Mb}] / \% \mathrm{PO}$ slope of the first linear segment of the double linear regression function was significantly $(P<0.05)$ steeper in T2D than controls $(1.81 \pm 0.61$ vs $1.35 \pm 0.43)$. Both groups displayed a near-plateau in $\Delta[\mathrm{HHb}+\mathrm{Mb}]$ at an exercise intensity (\%PO) not different among them. Such findings suggest that a reduced $\mathrm{O}_{2}$ delivery to active muscles is an important underlying cause of exercise intolerance during a maximum graded test in middle-aged individuals with T2D.

Keywords: near-infrared spectroscopy, oxygen extraction, cycling, exercise tolerance, type 2 diabetes 


\section{Introduction}

Individuals with uncomplicated type 2 diabetes mellitus (T2D) demonstrate impairments in peak exercise capacity ( $\dot{\mathrm{V}}_{2 \text { peak }}$ ), an established clinical predictor of cardiovascular and allcause mortality (Kodama et al., 2009; Swift et al., 2013), in the region of 20\% (Baldi et al., 2003; Kiely et al., 2015; Mac Ananey et al., 2011; O'Connor et al., 2015; O'Connor et al., 2012; Regensteiner et al., 1998). Importantly, this impairment is independent of obesity and age, and present in the absence of clinically apparent cardiovascular disease (Green et al., 2015). Whilst the precise mechanisms for this diminished exercise capacity remain to be elucidated, it is likely the consequence of a complex array of pathophysiological changes at a central and/or peripheral level (Green et al., 2015; Poitras et al., 2018). Maximum $\dot{\mathrm{VO}}_{2}$, representative of the integration of the pulmonary, cardiovascular and muscular systems to uptake, transport and utilise $\mathrm{O}_{2}$ respectively, is governed by the oxygen cascade from the environment to the muscle mitochondria (Poole, 1997; Wagner et al., 1997), and is thus, consequent to the product of whole-body perfusive and diffusive $\mathrm{O}_{2}$ conductance. However, most commonly, the Fick relationship is determined either at the pulmonary level, or across the exercising limb(s), and is representative of pooled fractional $\mathrm{O}_{2}$ extraction across multiple compartments which may not necessarily reflect the discrete adjustments of $\mathrm{O}_{2}$ exchange within the microvasculature of the active muscle (Iannetta et al., 2017; Okushima et al., 2016; Spencer et al., 2012). As such, considering the matching of $\mathrm{O}_{2}$ delivery $\left(\mathrm{QO}_{2}\right)$-to- $\dot{\mathrm{VO}}_{2}$ and diffusive $\mathrm{O}_{2}$ conductance at the level of the active muscle vasculature during exercise is of great relevance when exploring the mechanistic bases for the decreased exercise tolerance observed in T2D.

Substantial evidence exists to suggest that peripheral $\mathrm{O}_{2}$ delivery in the lower limbs is impaired in individuals with uncomplicated T2D. For instance, the maximum leg haemodynamic and vasodilatory responses during an incremental calf plantar-flexion exercise (Kiely et al., 2014) as well as steady-state femoral artery blood flow measurements during cycling (Kingwell et al., 
2003) and knee extension exercise (Lalande et al., 2008) are reduced in men and women with uncomplicated T2D. Additionally, leg vascular conductance kinetics at the onset of heavyintensity plantar-flexion exercise (Kiely et al., 2014; MacAnaney et al., 2011), and quadriceps muscle microvascular blood flow kinetics during moderate cycling (Bauer et al., 2007) are impaired (i.e. slowed/blunted) in individuals with T2D free from cardiovascular disease. In contrast, Poitras et al. (2015) recently reported unaffected leg blood flow kinetics during knee extension/flexion exercise in individuals with T2D; although participants had a more advanced diabetes and history of cardiovascular disease, with their control group also having a similar history of cardiovascular disease/comorbidities (Poitras et al., 2015). In agreement with Poitras et al. (2015), Copp et al. (2010) found that locomotory muscle(s) blood flow during running was not decreased in the rat GK model of type 2 diabetes (Copp et al., 2010) despite grossly impaired microvascular perfusion at rest (Padilla et al., 2006).

It is therefore plausible that the maldistribution of active muscle blood flow in individuals with uncomplicated T2D (Kiely et al., 2014; MacAnaney et al., 2011), and subsequently a decreased microvascular partial pressure of $\mathrm{O}_{2}\left(\mathrm{P} v_{2} \mathrm{O}_{2}\right)$ (Padilla et al., 2007), would mandate an increased reliance on fractional $\mathrm{O}_{2}$ extraction in the exercising muscle in an effort to achieve a given increase in $\dot{\mathrm{V}}_{2}$. The use of near-infrared spectroscopy (NIRS) during exercise permits a noninvasive assessment of microvascular $\mathrm{O}_{2}$ extraction (DeLorey et al., 2003). By measuring the concentration changes in deoxygenated haemoglobin and myoglobin $(\Delta[\mathrm{HHb}+\mathrm{Mb}])$, an estimate of fractional $\mathrm{O}_{2}$ extraction is possible. NIRS, therefore, provides insights into the dynamic balance between regional $\mathrm{QO}_{2}$ and $\dot{\mathrm{VO}}_{2}$ at the level of the microvasculature (Spencer et al., 2012), the determining factor for Pmvoz. Accordingly, investigating the dynamic response of $[\mathrm{HHb}+\mathrm{Mb}]$ within the microcirculation of the exercising muscles during a ramp incremental test may offer insight into pathophysiological mechanisms potentially implicated in the reduced exercise capacity in T2D. In the present study the profile of $\% \Delta[\mathrm{HHb}+\mathrm{Mb}]$ during a ramp 
incremental test was characterized using a function including two linear segments; the 'doublelinear model' (Vieth, 1989) as it has been proffered to best characterise this profile (Spencer et al., 2012). In the first segment, a linear increase in $\% \Delta[\mathrm{HHb}+\mathrm{Mb}]$ relative to changes in work rate occurs, representing the increasing reliance on $\mathrm{O}_{2}$ extraction relative to metabolic demand. This culminates at a 'breakpoint' $(\Delta[\mathrm{HHb}+\mathrm{Mb}]-B P)$, from which a "plateau-like" response ensues despite the continued increase in work rate. The breakbpoint has been associated with transitions in exercise intensity domains between heavy to severe-intensity exercise (Bellotti et al., 2013; Keir et al., 2015). This plateau in the $[\mathrm{HHb}+\mathrm{Mb}]$ signal does not indicate the upper limit of $\mathrm{O}_{2}$ extraction during incremental tests, and it seems to be connected to the redistribution of blood flow towards the active tissues once this upper boundary of exercise is achieved (Inglis et al., 2017).

The aim of the present study was to explore the influence of T2D on the profile of local muscle fractional $\mathrm{O}_{2}$ extraction, as indicated by the NIRS-derived $\Delta[\mathrm{HHb}+\mathrm{Mb}]$ response. We hypothesized that individuals with T2D would display an accelerated muscle deoxygenation response throughout the ramp incremental exercise bout. This would be depicted by a steeper primary slope of the double linear equation, thereby signifying an increased dependence on $\mathrm{O}_{2}$ extraction for providing adequate $\dot{\mathrm{VO}}_{2}$ at a given work rate. To avoid the potential effects of aging on the T2D-related impairments on exercise tolerance previously established in men (O'Connor et al., 2015; Wilkerson et al., 2011) we limited the age of participants to $<55 \mathrm{yr}$.

\section{Methods}

\subsection{Participants}

Thirty four individuals, 17 with uncomplicated T2D (12 males, 5 females), and 17 age- and BMI-matched controls (ND) (12 males, 5 females) volunteered to participate in this study. The age range of all participants was between 36 and 55 yr. (Table 1). Participants in the control 
group (ND) were recruited from the general population, whilst participants with T2D were

120 recruited from the diabetes outpatient clinics of St. Columcille's Hospital (Louglinstown, Co.

Dublin) and St. Vincent's University Hospital (SVUH, Dublin 4), following chart review. Five female participants were premenopausal (2 T2D, $3 \mathrm{ND}$ ) and 5 were postmenopausal (3 T2D, 2 ND) not undergoing hormone replacement therapy. All participants were non-smokers and had not smoked during the 12-month period preceding the study. Individuals with T2D had a clinical history of diabetes of between 2 to 9.5 years, with adequately controlled $\mathrm{HbA}_{1 \mathrm{c}}$ levels $(<10 \%)$ (Table 1) and were not taking insulin or beta-blockers. Two of the controls were on prescriptive medications (statins, $n=2$ ), and with the exception of one participant, all participants with T2D were taking oral $(n=15)$ and/or subcutaneous $(n=1)$ hypoglycaemic prescription medications (metformin monotherapy, $n=9$; metformin \& sulphonylurea, $n=3$; metformin \& thiazolidinedione, $n=1$; glucagon-like peptide $1, n=1$; sodium glucose cotransporter 2 inhibitors, $n=4$ ). In addition, a subgroup of individuals with T2D were taking antihypertensive prescription drugs (angiotensin converting enzyme inhibitor, $n=4$; angiotensin II receptor blocker, $n=2$; calcium channel blocker, $n=5)$ and statins $(n=6)$.

At the commencement of the present study, individuals with T2D displayed no clinical evidence of ischemic heart disease (normal ECG during treadmill stress test following the Bruce protocol), peripheral arterial disease $(0.9<\mathrm{ABI}<1.3)$, kidney dysfunction (urine protein $<$ $200 \mathrm{mg} / \mathrm{dl}$ ), or liver dysfunction (urine creatinine levels $<2.2 \mathrm{mg} / \mathrm{dl}$ ). Participants were classified as physically inactive by self-report $\left(\leq 1.5\right.$ h.week ${ }^{-1}$ of moderate-intensity exercise in the preceding 6 months), which was confirmed by the use of 5-day RT3 triaxial accelerometery

141 (Stayhealthy Inc, CA) in a subset of participants (Table 1) (Rowlands et al., 2004). All participants provided written informed consent before commencement, and the study was 
144 Dublin, and St Vincent's Healthcare Ethics and Medical Research Committee, and conducted 145 in accordance with the Declaration of Helsinki (2008).

\subsubsection{Overview.}

Following a satisfactory completion of the 12-lead ECG stress test, participants were tested on one occasion either at St. Columcille's Hospital or the cardiovascular laboratory in Trinity College Dublin. Premenopausal participants were tested during the mid-follicular phase (days 5-12) of the menstrual cycle. All participants refrained from consuming alcohol, caffeine and non-prescribed nutritional supplements in the 24 hours prior to testing and constrained their exercise to normal activities of daily living. All participants performed a ramp incremental cycling test to exhaustion to determine $\dot{\mathrm{VO}}_{2 \text { peak }}$.

2.2.2. Ramp incremental cycling tests to exhaustion. The ramp incremental cycling test to exhaustion was performed in an upright position on an electrically braked cycle ergometer (Excalibur Sport; Lode B.V., Groningen, The Netherlands). Exercise was performed at an initial workload of $10 \mathrm{~W}$ for $2 \mathrm{~min}$. This was followed by $10-15 \mathrm{~W} \cdot \mathrm{min}^{-1}$ increments in PO in females or $10-25 \mathrm{~W} \cdot \mathrm{min}^{-1}$ increments in males (depending on stated activity levels), until volitional exhaustion. Pedal frequency was held constant at an individually selected cadence between 6075 revolutions per minute (rpm). Failure in a test was determined as a drop in cadence exceeding $10 \mathrm{rpm}$ for $>5 \mathrm{~s}$. Peak workload was determined according to the point of termination of the test. $\dot{\mathrm{V}} \mathrm{O}_{2 \text { peak }}$ was determined by identifying the highest 15 -s mean $\dot{\mathrm{V}} \mathrm{O}_{2}$ value recorded before the participant's volitional termination of the test. The ventilatory threshold (VT) was determined as the exercise level at which $\dot{\mathrm{V}}_{\mathrm{E}} / \dot{\mathrm{V}}_{2}$ exhibited a systematic exponential increase without a concomitant increase in $\dot{\mathrm{V}}_{\mathrm{E}} / \dot{\mathrm{VCO}}_{2}$ (Wasserman et al., 1973), and the deflection point of carbon dioxide output $\left(\dot{\mathrm{VCO}}_{2}\right)$ versus $\mathrm{O}_{2}$ uptake ( $\dot{\mathrm{VO}}_{2} ; \mathrm{V}$-slope method) (Amann et al., 2006; 
Beaver et al., 1986). The respiratory compensation point (RCP) was estimated by identifying

171 the second non-linear increase of $\dot{\mathrm{V}}_{\mathrm{E}}$ and $\dot{\mathrm{V}} \mathrm{CO}_{2}$, whereby an increase in $\dot{\mathrm{V}}_{\mathrm{E}} / \dot{\mathrm{VO}}_{2}$ was accompanied by an increase of $\dot{\mathrm{V}}_{\mathrm{E}} / \dot{\mathrm{V} C O}_{2}$ (Wasserman and McIlroy, 1964).

\subsection{Measurements}

During exercise participants wore a facemask to continuously collect expired air using an online metabolic system (Innocor, Innovision A/S, Odense, Denmark). Analysis of expired air allowed determination of pulmonary $\mathrm{O}_{2}$ uptake $\left(\dot{\mathrm{V}}_{2}\right)$, carbon dioxide output $\left(\dot{\mathrm{VCO}}_{2}\right)$, minute ventilation $\left(\dot{\mathrm{V}}_{\mathrm{E}}\right)$ and the respiratory exchange ratio (RER) breath by breath. Heart rate was recorded every 5 s (Polar S610i, Polar Ltd, Finland), with peak HR defined as the highest heart rate attained within the last $15 \mathrm{~s}$ of the point of termination of the test. Beat-to-beat systolic and diastolic blood pressure was continuously monitored throughout the exercise protocol using the volume clamp method at the level of the finger (Finometer, Finepress Medical Systems B.V. the Netherlands). MAP was calculated from systolic and diastolic pressures (MAP: 0.33 systolic $\mathrm{BP}+0.66$ diastolic $\mathrm{BP})$. Peak $\mathrm{BP}$ was expressed as the highest 15 -second mean pressure obtained before the participant's volitional termination of the test.

A continuous wave NIRS system (Hamamatsu Niro 200Nx; Hamamatsu Photonics, Hamamatsu, Japan), was used to non-invasively determine the oxygenation status of the right quadricep's vastus lateralis (VL) muscle. This was determined using the spatially resolved spectroscopy (SRS) technique and modified Beer-Lambert (MBL) principle with three wavelengths of emitting light $(\lambda=735,810$, and $850 \mathrm{~nm})$. The theoretical basis of NIRS and its use in exercise measurements have been described in detail elsewhere (Ferrari et al., 2011). Briefly, this technique estimates the optical density changes of deoxygenated haemoglobin and myoglobin $(\mathrm{HHb}+\mathrm{Mb})$ based on the $\mathrm{O}_{2}$ dependency of absorption changes for near-infrared light in these proteins. As the VL muscle is a dominant locomotor muscle during cycling 
(Laplaud et al., 2006), the present study examined the $\Delta[\mathrm{HHb}+\mathrm{Mb}]$ ) profiles of the right $\mathrm{VL}$ muscle. After shaving the skin, the probes were placed on the belly of the muscle $(5-8 \mathrm{~cm}$ above the lateral femoral condyle), parallel to the major axis of the thigh with a $3 \mathrm{~cm}$ spacing between the emitter and receiver. The probes were housed in a black rubber holder and secured on the skin surface with bi-adhesive tape and then covered with a dark elastic bandage, which minimised extraneous movement and the intrusion of stray light throughout the exercise protocol. Since the depth of the measured area is estimated to be between one-half and onethird of the distance between the emitter and the receiver $(\sim 1.5 \mathrm{~cm})$ (Ferrari et al., 2004; Van Beekvelt et al., 2001), the thickness of the skin and adipose tissue at the site of the probe placement was measured via 2D ultrasound operating in B-mode (Zonare Ultra Smart Cart, Software version 4.7, USA). This was to ensure that data largely represented absorption of nearinfrared light in muscle tissue and not in subcutaneous fat.

\subsection{Data analysis}

2.4.1. Muscle deoxygenation. The NIRS-derived signal was normalised whereby the unloaded exercise baseline value was adjusted to zero ('zero set'). Thus the NIRS data are presented as a relative change from the baseline- to the end-exercise values. As such $0 \%$ represents the mean steady-state value of the last $30 \mathrm{~s}$ of the unloaded cycling and $100 \%$ represents the highest mean value of the last $30 \mathrm{~s}$ of any work rate. This was done given the uncertainty of the optical path length in the VL at rest and during exercise, so, data are presented as normalised delta units $\Delta[\mathrm{HHb}+\mathrm{Mb}]$. Prior to analysis, NIRS data were averaged to give $1 \mathrm{~s}$ intervals. The second-bysecond $[\mathrm{HHb}+\mathrm{Mb}]$ data was averaged by applying a five-point moving average and then normalised to the peak amplitude of the response $(\% \Delta[\mathrm{HHb}+\mathrm{Mb}])$. The $[\mathrm{HHb}+\mathrm{Mb}]$ response dynamics were expressed in relation to relative power output (\%PO) prior to curve fitting. Therefore, individual profiles were plotted as a function of \%PO and characterised by a linear function with two terms to establish the slope of increase of deoxygenation $\left(\right.$ Slope $\left._{1}\right)$, plateau as 
maximal exercise was approached (Slope 2 ), and the break point $(B P)$ located between the increasing deoxygenation and its plateau. The double linear function was applied using TableCurve 2D (Systat Software, USA) as:

$$
y=a+b * x-c *(x-d) * f
$$

$f=i f(x<d, 0,1)$

where $a$ and $b$ represent the y-intercept and slope of the first linear function (slope 1 ), $d$ is the time delay or $B P$ where the segments intersect, with the slope of the second linear function $\left(\right.$ slope $\left._{2}\right)$ being calculated from the parameter estimates of $b$ and $c\left(\right.$ slope $\left._{2}=b-c\right)$.

\subsection{2. $\triangle \dot{V} \mathrm{O}_{2} / \triangle P O$}

The rate of change $\dot{\mathrm{VO}}_{2}$ relative to $\mathrm{PO}$ during ramp incremental exercise reflects the capacity of aerobic metabolism to adjust to the non-steady state conditions incurred during a ramp incremental protocol. Initially, the mean response time (MRT) of ramp incremental exercise was estimated using the approach recently described by Iannetta et al. (2019). Briefly, we determined the average steady-state $\dot{\mathrm{V}} \mathrm{O}_{2}$ corresponding to three separate bouts of moderateintensity constant-power outputs (performed on a separate visit), and we then compared the ramp-derived power output associated with that $\dot{\mathrm{VO}}_{2}$ to the constant-power output that elicited that $\dot{\mathrm{VO}}_{2}$ (Iannetta et al., 2019). The difference between these power outputs was converted to the time to retrieve the time-interval corresponding to MRT. The breath by breath $\dot{\mathrm{VO}}_{2}$ data were averaged over $15 \mathrm{~s}$ intervals and plotted as a function of work rate after applying the MRT to reflect the increase in aerobic metabolism $\left(\Delta \dot{\mathrm{V}}_{2}\right)$ for each increase in power output $(\Delta \mathrm{PO})$. From this the $\Delta \dot{\mathrm{VO}}_{2} / \Delta \mathrm{PO}$ slope was calculated over the same range of $\mathrm{PO}$ as used to determine the first $\% \Delta[\mathrm{HHb}+\mathrm{Mb}] / \% \mathrm{PO}$ slope (i.e parameter $b$ or slope ${ }_{1}$ ) as described above. 


\subsection{Statistical analyses}

249 Statistical analysis was performed using the software SigmaPlot version 12.5 (Systat Software,

250 Point Richmond, CA). Prior to analysis, normal Gaussian distribution of the data was assessed

251 using the Shapiro-Wilk's test. Physical characteristics and NIRS-derived muscle deoxygenation

252 responses between groups were compared using unpaired 2-tailed Student's t-test for

253 parametric analyses, or the Mann-Whitney $\mathrm{U}$ test for non-parametric analyses. Based on $a$

254 priori evidence on the pre-determined reduced functional exercise capacity in individuals with

255 uncomplicated T2D, the peak physiological responses between groups were compared using

256 unpaired 1-tailed Student's t-test for parametric analyses, or the Mann-Whitney U test for non-

257 parametric analyses. Correlations between variables were established using the Peaarson

258 product-moment correlation coefficient (Pearson r). Statistical significance was accepted at a $P$

$259 \leq 0.05$. All values are expressed as means \pm standard deviation $(\mathrm{SD})$ or as median and

260 interquartile ranges for data that were deemed not normally distributed.

261

262

\section{Results}

263

3.1. Physical characteristics and activity levels.

264 Participants' physical characteristics and activity levels are shown in Table 1. Both groups were

265 well matched according to sex, age, body mass and BMI. Inactivity levels did not differ between groups, but individuals with T2D recorded higher light intensity activity levels. As expected,

267 participants with $\mathrm{T} 2 \mathrm{D}$ displayed higher $\mathrm{HbA}_{1 \mathrm{c}}$ and fasting plasma glucose levels. They also had 268 higher total cholesterol than the controls.

\subsection{Performance data from ramp incremental cycling test}

271 Relative $\dot{\mathrm{V}} \mathrm{O}_{2 \text { peak }}\left(\right.$ mean difference $\left.=6.14 \mathrm{~mL} \cdot \mathrm{kg}^{-1} \cdot \mathrm{min}^{-1}\right)$, absolute $\dot{\mathrm{V}} \mathrm{O}_{2 \text { peak }}($ mean difference $=$

2720.42 L. min $\left.^{-1}\right)$ and peak PO were significantly $(P<0.05)$ reduced in individuals with T2D 
273

274

275

276

277

278

280

281

282

283

284

285

286

287

288

289

290

291

292

293

294

295

296

297

compared with controls (Table 2). In addition, $\dot{\mathrm{V}} \mathrm{O}_{2}$ at $\mathrm{VT}$ and $\dot{\mathrm{V}} \mathrm{O}_{2}$ at $\mathrm{RCP}$ were also significantly lower in T2D $(P<0.05)$ compared with controls (Table 2).

\subsection{NIRS-derived $[H H b+M b]$ response dynamics and correlations}

Group mean parameter estimates from the double linear model of the $\% \Delta[\mathrm{HHb}+\mathrm{Mb}]$ profile as a function of normalised power output (\%PO) are displayed in Table 3. Individual representative profiles of the modelled $[\mathrm{HHb}+\mathrm{Mb}]$ response dynamics as a function of $\% \mathrm{PO}$ are displayed in Fig 1, while group mean responses are shown in Fig 2. Due to a technical error with the NIRS data (i.e. the entire $[\mathrm{HHb}+\mathrm{Mb}]$ responses were negative instead of positive), data from 6 participants ( 3 controls: 2 males, 1 female; and 3 participants with T2D: 2 males, 1 female). were excluded from the analyses. The slope of the first linear regression function $\left(\right.$ slope $\left._{1}\right)$ used to establish the dynamic adjustment of $[\mathrm{HHb}+\mathrm{Mb}]$ was significantly steeper $(P<$ 0.05) in participants with T2D than the controls (Table 3, Fig 3). In addition, in T2D slope 1 was significantly correlated with absolute $\dot{\mathrm{V}} \mathrm{O}_{2 \text { peak }}(\mathrm{r}=-0.67, P=0.009)$, relative $\dot{\mathrm{V}}_{2 \text { peak }}(\mathrm{r}=-0.64$; $P=0.013)$ and peak PO $(\mathrm{r}=-0.74 ; P=0.003)$; whereas slope 1 was not correlated with these variables in ND controls $(\mathrm{r}=0.132, P=0.65 ; \mathrm{r}=0.01, P=0.97 ; \mathrm{r}=0.155, P=0.60$; respectively). Correlations between slope ${ }_{1}$ and absolute $\dot{\mathrm{V}} \mathrm{O}_{2 \text { peak }}$ for both groups are shown in Fig 4. The exclusion of these 6 participants did not affect the physical characteristics of each group (i.e. they were matched in terms of age, body composition and activity levels) or the peak exercise responses between groups.

\section{4. $\triangle \dot{V} O_{2} / \triangle P O$}

The rate of change in $\dot{\mathrm{V}} \mathrm{O}_{2} / \mathrm{PO}$ was not significantly different during the ramp incremental exercise between the T2D and ND groups with no observed differences in slopes $(9.3 \pm 3.4$ vs. $9.6 \pm 1.1 \mathrm{~mL} \cdot \mathrm{min}^{-1} \cdot \mathrm{W}^{-1}$ respectively, $\left.P=0.23\right)$ 


\section{Discussion}

300 The principal original finding of the present investigation was that individual with T2D demonstrated a significantly steeper primary slope of the bi-linear regression used to establish the dynamic adjustment of $[\mathrm{HHb}+\mathrm{Mb}]$ during a ramp incremental exercise compared with controls. Concomitant with the reduced $(\sim 21 \%) \dot{\mathrm{V}}_{2 \text { peak }}$ responses observed in individuals with T2D compared with controls herein and previously (Baldi et al., 2003; Kiely et al., 2015; Mac Ananey et al., 2011; O'Connor et al., 2015; O'Connor et al., 2012; Regensteiner et al., 1998), such adjustment of $[\mathrm{HHb}+\mathrm{Mb}]$ provides further insight into pathophysiological mechanisms potentially responsible for the reduced functional capacity in this clinical population. Given that overall, the objectively measured physical activity levels did not differ between groups, the exaggerated exercise intolerance is likely not affected by differences in activity levels. Therefore, in agreement with our hypothesis, the present study suggests that T2D alters the profile of muscle fractional $\mathrm{O}_{2}$ extraction during ramp incremental cycle exercise. Specifically, T2D induced a greater reliance on normalized $\mathrm{O}_{2}$ extraction for a given normalized PO up to the $[\mathrm{HHb}+\mathrm{Mb}]-\mathrm{BP}$ (i.e. larger slope $_{1}$ ), and importantly, slope ${ }_{1}$ was inversely correlated with peak exercise capacity in participants with T2D.

Accordingly, the accelerated muscle deoxygenation revealed by the steeper primary $\% \Delta[\mathrm{HHb}+\mathrm{Mb}] / \% \mathrm{PO}$ slope of the bi-linear regression indicates a reduced capacity to increase peripheral $\mathrm{O}_{2}$ delivery to meet increasing $\mathrm{O}_{2}$ demands. The expression of this response in relation to the absolute workload may provide misleading conclusions given a diseased population with an established exercise intolerance (i.e. lower peak PO) is being compared to a healthy, albeit obese, population. A steeper adjustment of $\Delta[\mathrm{HHb}+\mathrm{Mb}]$ would be expected in participants with T2D given their lower peak PO during the ramp incremental test. Thus, it is warranted to make comparisons amongst these populations in the context of relative intensity (i.e. as a function of $\mathrm{PO} \%$ ) (Murias et al., 2013). A reduced $\mathrm{PmvO}_{2}$ and intracellular $\mathrm{PO}_{2}$ will 
radically impact muscle metabolism by reducing [phosphocreatine] and elevating $[\mathrm{ADP}]_{\text {free }}$, $[\mathrm{Pi}],\left[\mathrm{H}^{+}\right]$and $[\mathrm{NADH}]$. This increased glycolysis will rely on finite glycogen stores culminating in premature muscular fatigue and ultimately increased exercise intolerance in this clinical population. It should be noted that owing to the generation of noisy $\dot{\mathrm{VO}}_{2}$ data in some of the participants, in the present study we were unable to assess the relationship of $\% \Delta[\mathrm{HHb}+\mathrm{Mb}]$ with $\% \dot{\mathrm{V}} \mathrm{O}_{2}$ responses.

These findings are in accordance with studies whereby $\mathrm{O}_{2}$ availability during incremental exercise is deliberately compromised. Specifically, where $\mathrm{O}_{2}$ delivery was manipulated via exercising in the supine posture and subsequently reducing perfusion pressure (DiMenna et al., 2010; Egaña et al., 2013). In particular, DiMenna et al. (2010) demonstrated a significantly steeper slope of the $\% \Delta[\mathrm{HHb}+\mathrm{Mb}] / \% \mathrm{PO}$ sigmoidal response profile in the supine compared with upright posture during a ramp incremental exercise, implying a greater reliance on $\mathrm{O}_{2}$ extraction for the same PO (DiMenna et al., 2010). Similarly, Behnke et al. (2002) reported $\mathrm{P}_{\mathrm{N} v \mathrm{O}_{2}}$ reductions at a given muscle stimulation intensity in the GK rodent model of T2D compared with healthy controls predicating either a reduced $\mathrm{O}_{2}$ diffusion across the capillarymyocyte space to the mitochondria or a lowered intramyocyte $\mathrm{PO}_{2}$ which would impair muscle metabolism and function (Behnke et al., 2002). Thus, the findings of the present study combined with the previously reported blunted microvascular blood flow responses at the onset of moderate-intensity cycling exercise in individuals with uncomplicated T2D (Bauer et al., 2007), strengthens the argument for reduced $\mathrm{O}_{2}$ delivery as a likely source of impairment in $\dot{\mathrm{V}} \mathrm{O}_{2}$ control in this population.

With evidence of an imbalance in $\mathrm{QO}_{2}$ relative to $\mathrm{PO}$ within the microvasculature during ramp incremental exercise in $\mathrm{T} 2 \mathrm{D}$, and the resultant lowered $\mathrm{P} m v o_{2}$, an impaired haemodynamic response can be posited as a potential mechanistic basis for the diminished exercise capacity 
herein. Indeed, the significant correlations observed between the initial slope of muscle

352 deoxygenation with $\dot{\mathrm{V}} \mathrm{O}_{2 \text { peak }}$ and peak PO in the group with T2D support this notion. In this

353

354 regard, the attenuated hyperaemic and haemodynamic response during maximum graded calf plantar flexion exercise demonstrated by this clinical population (Kiely et al., 2014) is of relevance. Specifically, Kiely et al. (2014) demonstrated that peak leg blood flow and the slope of leg blood flow relative to percentage peak force during an incremental calf exercise were significantly blunted in men and women with T2D. These reductions were accompanied by significantly lower (magnitude of $\sim 15 \%$ ) peak force relative to MVC during the calf graded test, which also coincided with a significant $(\sim 15 \%)$ reduction in $\dot{\mathrm{VO}}_{2 \text { peak }}$ during a graded cycling test in the same participants (Kiely et al., 2014). Therefore, the demonstration in the present study of a faster rise in the primary linear $\% \Delta[\mathrm{HHb}+\mathrm{Mb}] / \% \mathrm{PO}$ signal $\left(\right.$ slope $\left._{1}\right)$ in T2D compared with controls, combined with a similar rate of increase in $\dot{\mathrm{VO}}_{2}$ relative to PO (i.e. $\left.\Delta \dot{\mathrm{VO}}_{2} / \Delta \mathrm{PO}\right)$ extends the findings of a dampened hyperaemic response previously observed in isolated muscle groups to that of whole body exercise in uncomplicated T2D.

Although the mechanisms responsible for the altered profile of muscle fractional $\mathrm{O}_{2}$ extraction observed in individuals with T2D were not directly explored in this study, the-impaired vascular function extensively evidenced in T2D is a likely culprit. For instance, attenuated endotheliumdependent vasodilation of resistance vessels in both, the resting forearm (McVeigh et al., 1992; Williams et al., 1996), and the lower limb during cycle exercise (Kingwell et al., 2003) have been reported in individuals with uncomplicated T2D compared to controls. In addition tempered vasodilator responses of the vascular smooth muscle elicited subsequent to exogenous, direct-acting nitric oxide (NO) donors in the form of glyceryl trinitrate (McVeigh et al., 1992) and sodium nitroprusside (Kingwell et al., 2003; Williams et al., 1996) have also been reported in the respective T2D cohorts. It is pertinent to acknowledge, however, that in the absence of cardiac output (CO) data, we cannot exclude the possibility that impairments in 
cardiac function (Joshi et al., 2010; Regensteiner et al., 2009; Wilson et al., 2017a; Wilson et al., 2017b) could induce subsequent regional $\mathrm{O}_{2}$ delivery impediments; although peak $\mathrm{CO}$ is not significantly reduced in uncomplicated T2D (Baldi et al., 2003; Regensteiner et al., 2009). Moreover, factors beyond convective and diffusive $\mathrm{O}_{2}$ delivery may also be involved given that structural changes in the skeletal muscles of individuals with T2D havae been observed. Specifically, reductions in mitochondrial content ( 30\%) (Boushel et al., 2007; Ritov et al., 2005) and functional capacity ( 40\%) (Kelley et al., 2002; Ritov et al., 2005), as well as alterations in muscle fibre type (Marin et al., 1994), having an approximate 2-fold increase in type IIb fibres relative to type I (Mogensen et al., 2007) have been reported in T2D, although the functional evidence for this notion is unclear (Rabol et al., 2006).

Limitations of the present study should be acknowledged. Firstly, given the functional limitations of the NIRS technology utilised herein, we were unable to make direct comparisons of absolute concentration and changes in $\Delta[\mathrm{HHb}+\mathrm{Mb}]$ between individuals with and without T2D. However, $[\mathrm{HHb}+\mathrm{Mb}]$ possesses a time course similar to fractional $\mathrm{O}_{2}$ extraction (Koga et al., 2012). Secondly, the present findings relate to the evaluation of a single muscle, the VL, and as such, cannot wholly represent the skeletal muscle blood flow response to exercise. Also, the heterogeneity within an individual muscle is recognised; structurally, pertaining to vascularity and fibre type (Johnson et al., 1973), and functionally, relating to fibre recruitment, vascular control and blood flow (Behnke et al., 2003; Koga et al., 2011; McDonough et al., 2005). Thirdly, adipose tissue thickness at the site of measurement has the potential to influence NIRS measurements through its effect on the scattering properties of the tissue. As such, the thickness of the skin and adipose tissue was measured at the site of the interrogation via 2D ultrasound operating in B-mode, with no differences revealed between groups. The current findings are applicable to individuals $<55 \mathrm{yr}$, so, future studies should assess if these effects are also apparent in older people with T2D. 


\section{Conclusions}

405 The findings from the present study offer an insight into potential contributory mechanisms for 406 the consistently observed reduction in exercise capacity in T2D. The demonstration of a greater

407

408

409

410

411

412

413

414

415

416

417

This publication has emanated from research conducted with the financial support of the Health rate of $\mathrm{O}_{2}$ extraction for a given increase in $\mathrm{PO}$ suggests that a reduced $\mathrm{O}_{2}$ delivery within the microvasculature is an important underlying cause of exercise intolerance during a maximum graded test in T2D. This observation strengthens the notion that factors beyond central control also contribute to the diminished exercise tolerance of this clinical population. Such factors are most likely attributed to impairments in active muscle microvascular perfusion. Thus, exercise training interventions designed to benefit exercise tolerance in T2D should also focus on microvascular $\mathrm{O}_{2}$ delivery.

\section{Author contribution statement}

$\mathrm{NG}, \mathrm{JR}, \mathrm{ME}, \mathrm{DO}$ 'S and SG designed the study. $\mathrm{NG}, \mathrm{JR}$ and $\mathrm{AMcD}$ contributed to data collection. NG, JR, SG and ME performed the data analysis. NG, JR and ME performed the statistical analyses. NG and ME wrote the manuscript. All authors commented on the manuscript and approved the final version of the manuscript.

\section{Declarations of interest}

None.

$$
\text { Research Board (Grant No HRA_POR/2073/274). }
$$


Amann, M., Subudhi, A.W., Foster, C., 2006. Predictive validity of ventilatory and lactate thresholds for cycling time trial performance. Scand J Med Sci Sports 16 (1), 27-34.

Baldi, J.C., Aoina, J.L., Oxenham, H.C., Bagg, W., Doughty, R.N., 2003. Reduced exercise arteriovenous $\mathrm{O} 2$ difference in Type 2 diabetes. J Appl Physiol 94 (3), 1033-1038.

Bauer, T.A., Reusch, J.E., Levi, M., Regensteiner, J.G., 2007. Skeletal muscle deoxygenation after the onset of moderate exercise suggests slowed microvascular blood flow kinetics in type 2 diabetes. Diabetes Care 30 (11), 2880-2885.

Beaver, W.L., Wasserman, K., Whipp, B.J., 1986. A new method for detecting anaerobic threshold by gas exchange. J Appl Physiol 60 (6), 2020-2027.

Behnke, B.J., Kindig, C.A., McDonough, P., Poole, D.C., Sexton, W.L., 2002. Dynamics of microvascular oxygen pressure during rest-contraction transition in skeletal muscle of diabetic rats. Am J Physiol Heart Circ Physiol 283 (3), H926-932.

Behnke, B.J., McDonough, P., Padilla, D.J., Musch, T.I., Poole, D.C., 2003. Oxygen exchange profile in rat muscles of contrasting fibre types. J Physiol 549 (Pt 2), 597-605.

Bellotti, C., Calabria, E., Capelli, C., Pogliaghi, S., 2013. Determination of maximal lactate steady state in healthy adults: can NIRS help? Med Sci Sports Exerc 45 (6), 1208-1216.

Boushel, R., Gnaiger, E., Schjerling, P., Skovbro, M., Kraunsoe, R., Dela, F., 2007. Patients with type 2 diabetes have normal mitochondrial function in skeletal muscle. Diabetologia 50 (4), 790796.

Copp, S.W., Hageman, K.S., Behnke, B.J., Poole, D.C., Musch, T.I., 2010. Effects of type II diabetes on exercising skeletal muscle blood flow in the rat. J Appl Physiol (1985) 109 (5), 1347-1353.

DeLorey, D.S., Kowalchuk, J.M., Paterson, D.H., 2003. Relationship between pulmonary 02 uptake kinetics and muscle deoxygenation during moderate-intensity exercise. J Appl Physiol (1985) 95 (1), 113-120.

DiMenna, F.J., Bailey, S.J., Jones, A.M., 2010. Influence of body position on muscle deoxy[Hb+Mb] during ramp cycle exercise. Respir Physiol Neurobiol 173 (2), 138-145.

Egaña, M., Columb, D., O'Donnell, S., 2013. Effect of low recumbent angle on cycling performance, fatigue, and V O(2) kinetics. Med Sci Sports Exerc 45 (4), 663-673.

Ferrari, M., Mottola, L., Quaresima, V., 2004. Principles, techniques, and limitations of near infrared spectroscopy. Can J Appl Physiol 29 (4), 463-487.

Ferrari, M., Muthalib, M., Quaresima, V., 2011. The use of near-infrared spectroscopy in understanding skeletal muscle physiology: recent developments. Philos Trans A Math Phys Eng Sci 369 (1955), 4577-4590.

Green, S., Egana, M., Baldi, J.C., Lamberts, R., Regensteiner, J.G., 2015. Cardiovascular control during exercise in type 2 diabetes mellitus. J Diabetes Res 2015654204.

lannetta, D., Murias, J.M., Keir, D.A., 2019. A Simple Method to Quantify the V O2 Mean Response Time of Ramp-Incremental Exercise. Med Sci Sports Exerc 51 (5), 1080-1086.

lannetta, D., Qahtani, A., Millet, G.Y., Murias, J.M., 2017. Quadriceps Muscles O2 Extraction and EMG Breakpoints during a Ramp Incremental Test. Front Physiol 8686.

Inglis, E.C., lannetta, D., Murias, J.M., 2017. The plateau in the NIRS-derived [HHb] signal near the end of a ramp incremental test does not indicate the upper limit of $\mathrm{O} 2$ extraction in the vastus lateralis. Am J Physiol Regul Integr Comp Physiol 313 (6), R723-r729.

Johnson, M.A., Polgar, J., Weightman, D., Appleton, D., 1973. Data on the distribution of fibre types in thirty-six human muscles. An autopsy study. J Neurol Sci 18 (1), 111-129.

Joshi, D., Shiwalkar, A., Cross, M.R., Sharma, S.K., Vachhani, A., Dutt, C., 2010. Continuous, noninvasive measurement of the haemodynamic response to submaximal exercise in patients with diabetes mellitus: evidence of impaired cardiac reserve and peripheral vascular response. Heart 96 (1), 36-41. 
Keir, D.A., Fontana, F.Y., Robertson, T.C., Murias, J.M., Paterson, D.H., Kowalchuk, J.M., Pogliaghi, S., 2015. Exercise Intensity Thresholds: Identifying the Boundaries of Sustainable Performance. Med Sci Sports Exerc 47 (9), 1932-1940.

Kelley, D.E., He, J., Menshikova, E.V., Ritov, V.B., 2002. Dysfunction of mitochondria in human skeletal muscle in type 2 diabetes. Diabetes 51 (10), 2944-2950.

Kiely, C., O'Connor, E., O'Shea, D., Green, S., Egaña, M., 2014. Hemodynamic responses during graded and constant-load plantar flexion exercise in middle-aged men and women with type 2 diabetes. J Appl Physiol (1985) 117 (7), 755-764.

Kiely, C., Rocha, J., O'Connor, E., O'Shea, D., Green, S., Egana, M., 2015. Influence of menopause and Type 2 diabetes on pulmonary oxygen uptake kinetics and peak exercise performance during cycling. Am J Physiol Regul Integr Comp Physiol 309 (8), R875-883.

Kingwell, B.A., Formosa, M., Muhlmann, M., Bradley, S.J., McConell, G.K., 2003. Type 2 diabetic individuals have impaired leg blood flow responses to exercise: role of endotheliumdependent vasodilation. Diabetes Care 26 (3), 899-904.

Kodama, S., Saito, K., Tanaka, S., Maki, M., Yachi, Y., Asumi, M., Sugawara, A., Totsuka, K., Shimano, H., Ohashi, Y., Yamada, N., Sone, H., 2009. Cardiorespiratory fitness as a quantitative predictor of all-cause mortality and cardiovascular events in healthy men and women: a meta-analysis. Jama 301 (19), 2024-2035.

Koga, S., Kano, Y., Barstow, T.J., Ferreira, L.F., Ohmae, E., Sudo, M., Poole, D.C., 2012. Kinetics of muscle deoxygenation and microvascular $\mathrm{PO}(2)$ during contractions in rat: comparison of optical spectroscopy and phosphorescence-quenching techniques. J Appl Physiol (1985) 112 (1), 26-32.

Koga, S., Poole, D.C., Fukuoka, Y., Ferreira, L.F., Kondo, N., Ohmae, E., Barstow, T.J., 2011. Methodological validation of the dynamic heterogeneity of muscle deoxygenation within the quadriceps during cycle exercise. Am J Physiol Regul Integr Comp Physiol 301 (2), R534-541.

Lalande, S., Gusso, S., Hofman, P.L., Baldi, J.C., 2008. Reduced leg blood flow during submaximal exercise in type 2 diabetes. Med Sci Sports Exerc 40 (4), 612-617.

Laplaud, D., Hug, F., Grelot, L., 2006. Reproducibility of eight lower limb muscles activity level in the course of an incremental pedaling exercise. J Electromyogr Kinesiol 16 (2), 158-166.

Mac Ananey, O., Malone, J., Warmington, S., O'Shea, D., Green, S., Egaña, M., 2011. Cardiac output is not related to the slowed 02 uptake kinetics in type 2 diabetes. Med Sci Sports Exerc 43 (6), 935-942.

MacAnaney, O., Reilly, H., O'Shea, D., Egaña, M., Green, S., 2011. Effect of type 2 diabetes on the dynamic response characteristics of leg vascular conductance during exercise. Diab Vasc Dis Res 8 (1), 12-21.

Marin, P., Andersson, B., Krotkiewski, M., Bjorntorp, P., 1994. Muscle fiber composition and capillary density in women and men with NIDDM. Diabetes Care 17 (5), 382-386.

McDonough, P., Behnke, B.J., Padilla, D.J., Musch, T.I., Poole, D.C., 2005. Control of microvascular oxygen pressures in rat muscles comprised of different fibre types. J Physiol 563 (Pt 3), 903913.

McVeigh, G.E., Brennan, G.M., Johnston, G.D., McDermott, B.J., McGrath, L.T., Henry, W.R., Andrews, J.W., Hayes, J.R., 1992. Impaired endothelium-dependent and independent vasodilation in patients with type 2 (non-insulin-dependent) diabetes mellitus. Diabetologia 35 (8), 771-776.

Mogensen, M., Sahlin, K., Fernstrom, M., Glintborg, D., Vind, B.F., Beck-Nielsen, H., Hojlund, K., 2007. Mitochondrial respiration is decreased in skeletal muscle of patients with type 2 diabetes. Diabetes 56 (6), 1592-1599.

Murias, J.M., Keir, D.A., Spencer, M.D., Paterson, D.H., 2013. Sex-related differences in muscle deoxygenation during ramp incremental exercise. Respir Physiol Neurobiol 189 (3), 530-536.

O'Connor, E., Green, S., Kiely, C., O'Shea, D., Egana, M., 2015. Differential effects of age and type 2 diabetes on dynamic vs. peak response of pulmonary oxygen uptake during exercise. J Appl Physiol (1985) 118 (8), 1031-1039. 

performance and oxygen uptake kinetics in middle-aged men and women with type 2 diabetes. Am J Physiol Regul Integr Comp Physiol 303 (1), R70-76.

Okushima, D., Poole, D.C., Barstow, T.J., Rossiter, H.B., Kondo, N., Bowen, T.S., Amano, T., Koga, S., 2016. Greater V O2peak is correlated with greater skeletal muscle deoxygenation amplitude and hemoglobin concentration within individual muscles during ramp-incremental cycle exercise. Physiol Rep 4 (23).

Padilla, D.J., McDonough, P., Behnke, B.J., Kano, Y., Hageman, K.S., Musch, T.I., Poole, D.C., 2006. Effects of Type II diabetes on capillary hemodynamics in skeletal muscle. Am J Physiol Heart Circ Physiol 291 (5), H2439-2444.

Padilla, D.J., McDonough, P., Behnke, B.J., Kano, Y., Hageman, K.S., Musch, T.I., Poole, D.C., 2007. Effects of Type II diabetes on muscle microvascular oxygen pressures. Respir Physiol Neurobiol 156 (2), 187-195.

Poitras, V.J., Bentley, R.F., Hopkins-Rosseel, D.H., LaHaye, S.A., Tschakovsky, M.E., 2015. Independent effect of type 2 diabetes beyond characteristic comorbidities and medications on immediate but not continued knee extensor exercise hyperemia. J Appl Physiol (1985) 119 (3), 202-212.

Poitras, V.J., Hudson, R.W., Tschakovsky, M.E., 2018. Exercise intolerance in Type 2 diabetes: is there a cardiovascular contribution? J Appl Physiol (1985) 124 (5), 1117-1139.

Poole, D.C., 1997. Influence of exercise training on skeletal muscle oxygen delivery and utilization. In Crystal RG, West JB, Weibel ER, Barnes PJ, editors. The Lung: Scientific Foundations. New York: Raven Press. . 1957-1967.

Rabol, R., Boushel, R., Dela, F., 2006. Mitochondrial oxidative function and type 2 diabetes. Appl Physiol Nutr Metab 31 (6), 675-683.

Regensteiner, J.G., Bauer, T.A., Reusch, J.E., Brandenburg, S.L., Sippel, J.M., Vogelsong, A.M., Smith, S., Wolfel, E.E., Eckel, R.H., Hiatt, W.R., 1998. Abnormal oxygen uptake kinetic responses in women with type II diabetes mellitus. J Appl Physiol 85 (1), 310-317.

Regensteiner, J.G., Bauer, T.A., Reusch, J.E., Quaife, R.A., Chen, M.Y., Smith, S.C., Miller, T.M., Groves, B.M., Wolfel, E.E., 2009. Cardiac dysfunction during exercise in uncomplicated type 2 diabetes. Med Sci Sports Exerc 41 (5), 977-984.

Ritov, V.B., Menshikova, E.V., He, J., Ferrell, R.E., Goodpaster, B.H., Kelley, D.E., 2005. Deficiency of subsarcolemmal mitochondria in obesity and type 2 diabetes. Diabetes 54 (1), 8-14.

Rowlands, A.V., Thomas, P.W., Eston, R.G., Topping, R., 2004. Validation of the RT3 triaxial accelerometer for the assessment of physical activity. Med Sci Sports Exerc 36 (3), 518-524.

Spencer, M.D., Murias, J.M., Paterson, D.H., 2012. Characterizing the profile of muscle deoxygenation during ramp incremental exercise in young men. Eur J Appl Physiol 112 (9), 3349-3360.

Swift, D.L., Lavie, C.J., Johannsen, N.M., Arena, R., Earnest, C.P., O'Keefe, J.H., Milani, R.V., Blair, S.N., Church, T.S., 2013. Physical activity, cardiorespiratory fitness, and exercise training in primary and secondary coronary prevention. Circ J 77 (2), 281-292.

Van Beekvelt, M.C., Colier, W.N., Wevers, R.A., Van Engelen, B.G., 2001. Performance of nearinfrared spectroscopy in measuring local $\mathrm{O}(2)$ consumption and blood flow in skeletal muscle. J Appl Physiol (1985) 90 (2), 511-519.

Vieth, E., 1989. Fitting piecewise linear regression functions to biological responses. J Appl Physiol (1985) 67 (1), 390-396.

Wagner, P.D., Hoppeler, H., Saltin, B., 1997. Determinants of maximal oxygen uptake. In Crystal RG, West JB, Weibel ER, Barnes PJ, editors. The Lung: Scientific Foundations. New York: Raven Press. 2033-2204.

Wasserman, K., Mcllroy, M.B., 1964. DETECTING THE THRESHOLD OF ANAEROBIC METABOLISM IN CARDIAC PATIENTS DURING EXERCISE. Am J Cardiol 14 844-852.

Wasserman, K., Whipp, B.J., Koyl, S.N., Beaver, W.L., 1973. Anaerobic threshold and respiratory gas exchange during exercise. J Appl Physiol 35 (2), 236-243. 
Wilkerson, D.P., Poole, D.C., Jones, A.M., Fulford, J., Mawson, D.M., Ball, C.I., Shore, A.C., 2011. Older type 2 diabetic males do not exhibit abnormal pulmonary oxygen uptake and muscle oxygen utilization dynamics during submaximal cycling exercise. Am J Physiol Regul Integr Comp Physiol 300 (3), R685-692.

Williams, S.B., Cusco, J.A., Roddy, M.A., Johnstone, M.T., Creager, M.A., 1996. Impaired nitric oxidemediated vasodilation in patients with non-insulin-dependent diabetes mellitus. J Am Coll Cardiol 27 (3), 567-574.

Wilson, G.A., Wilkins, G.T., Cotter, J.D., Lamberts, R.R., Lal, S., Baldi, J.C., 2017a. Impaired ventricular filling limits cardiac reserve during submaximal exercise in people with type 2 diabetes. Cardiovasc Diabetol 16 (1), 160.

Wilson, G.A., Wilson, L.C., Lamberts, R.R., Majeed, K., Lal, S., Wilkins, G.T., Baldi, J.C., 2017b. betaAdrenergic Responsiveness in the Type 2 Diabetic Heart: Effects on Cardiac Reserve. Med Sci Sports Exerc 49 (5), 907-914.

595

596 
$598 \quad$ Figure captions

599 Figure 1: Representative profiles of the modelled $[\mathrm{HHb}+\mathrm{Mb}]$ response dynamics during ramp 600 incremental exercise for an individual without, and an individual with T2D when expressed as 601 a function of relative power output (PO\%). Double-linear regression models are superimposed 602 on the data. The first $\% \Delta[\mathrm{HHb}+\mathrm{Mb}] / \% \mathrm{PO}$ slope of the double linear regression is indicated 603 beside each curve. Note the relatively larger slope in the participant with T2D compared with 604 the control participant.

605

606 Figure 2: Group mean $\pm \mathrm{SD}$ normalised $[\mathrm{HHb}+\mathrm{Mb}]$ responses as a function of relative power 607 output (PO\%). Data are shown at 10\% PO intervals. Note the relatively steeper increase in $608[\mathrm{HHb}+\mathrm{Mb}]$ in the group with T2D compared with the control group.

609

610 Figure 3: Individual and mean $\pm \mathrm{SD}($ bar graph) responses of the first $\% \Delta[\mathrm{HHb}+\mathrm{Mb}] / \% \mathrm{PO}$

611 slope $\left(\mathrm{Slpoe}_{1}\right)$ of the double linear regression in the T2D and control groups.

612

613 Figure 4: Relationships between first $\% \Delta[\mathrm{HHb}+\mathrm{Mb}] / \% \mathrm{PO}$ slope $\left(\mathrm{Slpoe}_{1}\right)$ of the double linear 614 regression and $\dot{\mathrm{V}} \mathrm{O}_{2 \text { peak }}\left(\mathrm{mL} \cdot \mathrm{kg}^{-1} \cdot \mathrm{min}^{-1}\right)$ in participants with $\mathrm{T} 2 \mathrm{D}$ and ND controls. 
Figure 1

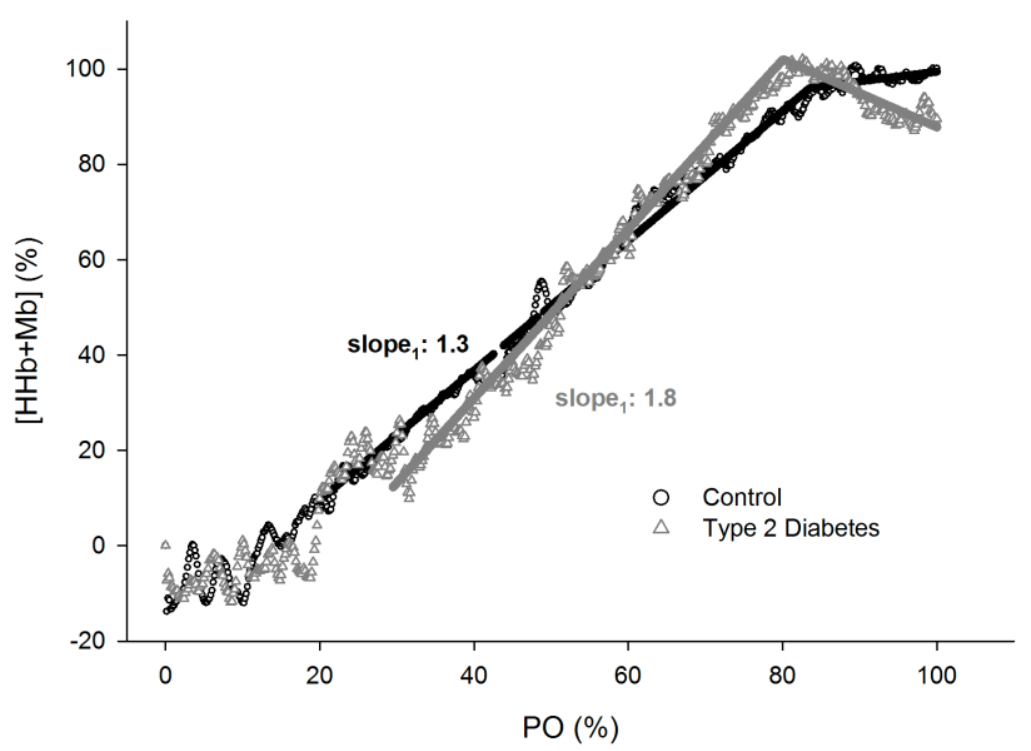

616

617 
Figure 2

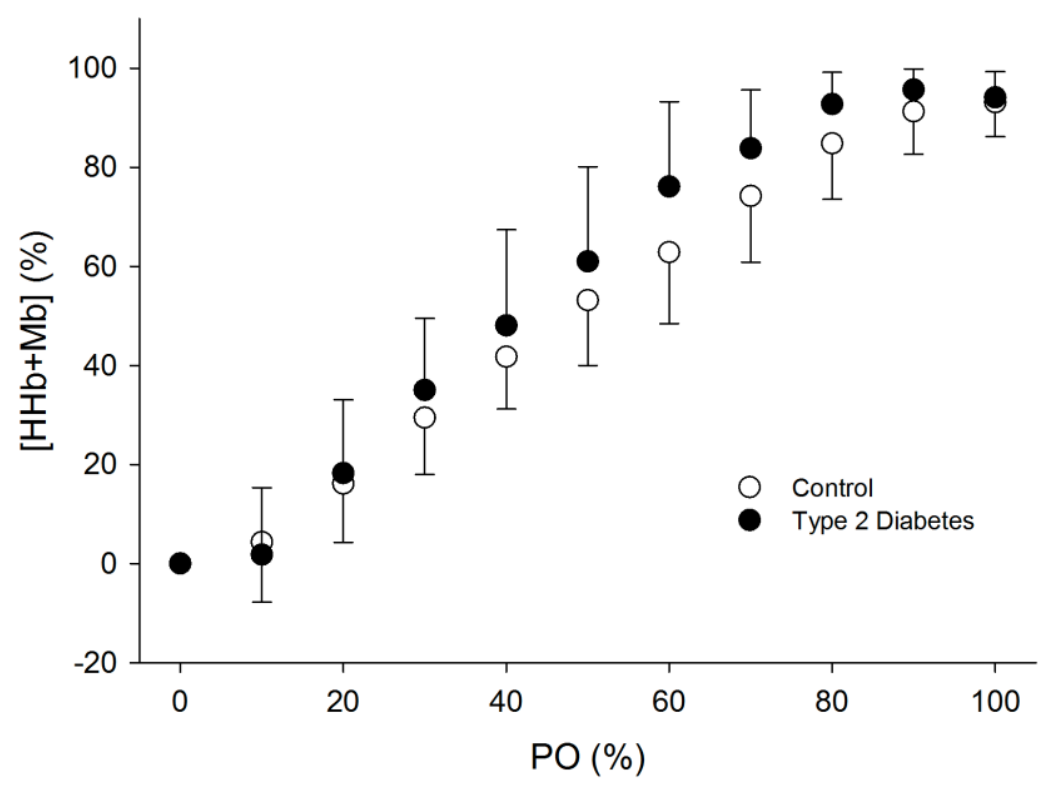

618

619 
Figure 3

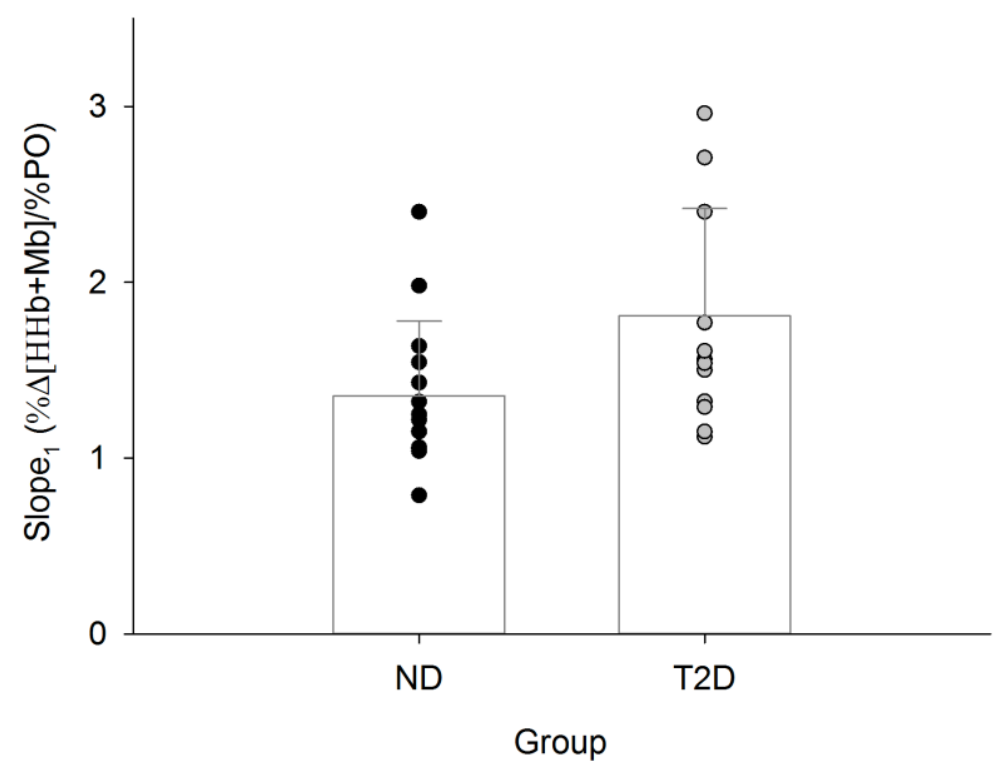

620

621 
Figure 4

T2D

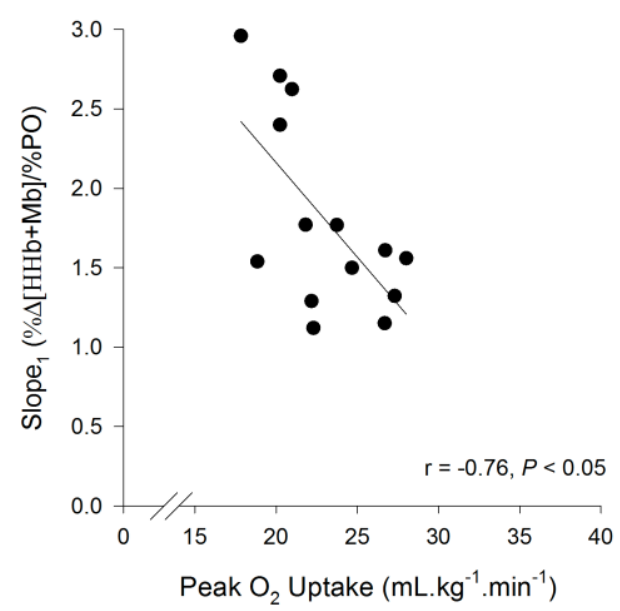

Control

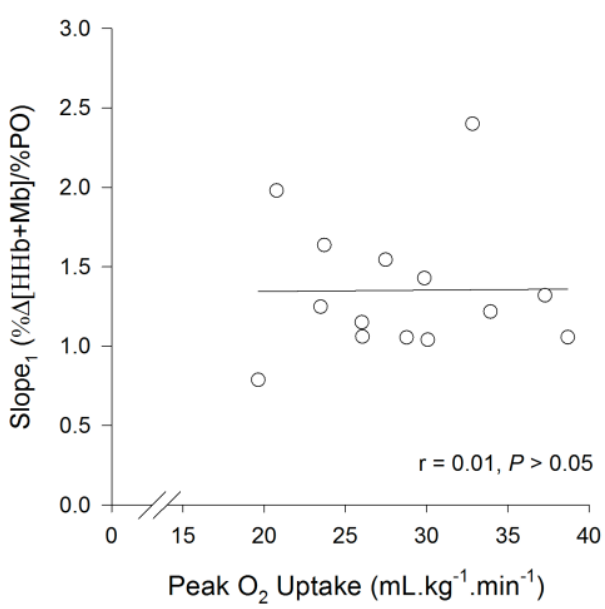

623 Alternative Fig 4 (no regression line in control

Figure 4
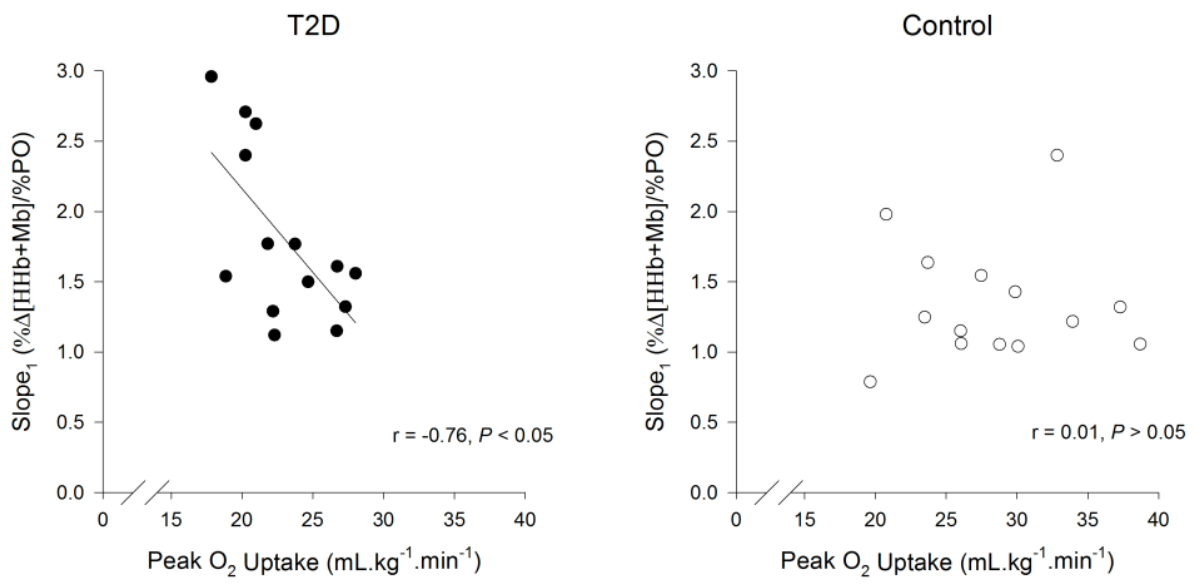
Table 1. Physical characteristics and activity levels.

\begin{tabular}{|c|c|c|c|}
\hline & ND & $\mathrm{T} 2 \mathrm{D}$ & $P$ value \\
\hline$n$ & 17 & 17 & \\
\hline \multicolumn{4}{|l|}{ Physical characteristics } \\
\hline Sex (male, female) & 12,5 & 12,5 & \\
\hline Age (yr) & $44 \pm 8$ & $48 \pm 7$ & 0.13 \\
\hline $\mathrm{BMI}\left(\mathrm{kg} \cdot \mathrm{m}^{-2}\right)$ & $30.8 \pm 3.5$ & $31.9 \pm 4.8$ & 0.46 \\
\hline Body Mass (kg) & $91.1 \pm 13.8$ & $95.8 \pm 18.3$ & 0.40 \\
\hline $\operatorname{HbA} 1 \mathrm{c}(\%)^{\mathrm{a}}$ & $5.1(0.5)^{*}$ & $6.8(0.9)$ & $<0.001$ \\
\hline FPG $\left(\mathrm{mmol} \cdot \mathrm{L}^{-1}\right)^{\mathrm{b}}$ & $4.0(0.4)^{*}$ & $7.4(2.9)$ & $<0.001$ \\
\hline Fat layer VL $(\mathrm{mm})^{\mathrm{c}}$ & $7.8 \pm 4.5$ & $5.9 \pm 1.6$ & 0.14 \\
\hline Time since diagnosis (yr) & & $5.7 \pm 3.7$ & \\
\hline Total cholesterol $\left(\mathrm{mmol} . \mathrm{L}^{-1}\right)^{\mathrm{d}}$ & $3.6 \pm 0.9^{*}$ & $4.4 \pm 0.7$ & 0.03 \\
\hline LDL-C $\left(\mathrm{mmol}^{\mathrm{L}} \mathrm{L}^{-1}\right)^{\mathrm{e}}$ & $2.0 \pm 0.7$ & $2.2 \pm 0.7$ & 0.50 \\
\hline HDL-C $\left(\mathrm{mmol}^{-L^{-1}}\right)^{\mathrm{d}}$ & $1.2 \pm 0.2$ & $1.35 \pm 0.3$ & 0.62 \\
\hline Triglycerides $\left(\mathrm{mmol} \mathrm{L}^{-1}\right)^{\mathrm{f}}$ & $1.1(0.9)^{\dagger}$ & $1.5(1.3)$ & 0.08 \\
\hline \multicolumn{4}{|l|}{ Habitual physical activity } \\
\hline Inactive $\left(\text { h.day }^{-1}\right)^{\mathrm{g}}$ & $18.9 \pm 1.3$ & $18.0 \pm 1.0$ & 0.15 \\
\hline Light $\left(\text { h.day }^{-1}\right)^{\mathrm{g}}$ & $4.2 \pm 1.0^{*}$ & $5.3 \pm 1.1$ & 0.05 \\
\hline Moderate $\left(\text { h.day }^{-1}\right)^{\mathrm{g}}$ & $0.7 \pm 0.4$ & $0.6 \pm 0.6$ & 0.69 \\
\hline Vigorous $\left(\text { h.day }{ }^{-1}\right)^{\mathrm{g}}$ & $0.2(0.2)$ & $0.1(0.1)$ & 0.17 \\
\hline
\end{tabular}

627

628
Mean \pm SD values are shown in normal font for variables which were normally distributed; whereas median (and interquartile range) values are shown in italic font for variables which showed significant skewness and were not normally distributed in one or both groups. BMI, body mass index; $\mathrm{HbA}_{1 \mathrm{c}}$, glycosylated haemoglobin; FPG, fasting plasma glucose; VL, vastus lateralis; LDL-C, low-density lipoprotein cholesterol; HDL$\mathrm{C}$, high-density lipoprotein cholesterol. Some variables have missing values and the sample sizes with codes are shown below. *Significantly different than T2D $(P \leq 0.05)$. †Tendency towards a difference than T2D $(P \leq 0.10)$.

${ }^{\mathrm{a}}=7$ (ND) and $15(\mathrm{~T} 2 \mathrm{D}) ;{ }^{\mathrm{b}}=10$ (ND) and 13 (T2D); ${ }^{\mathrm{c}}=13$ (ND) and 15 (T2D); ${ }^{\mathrm{d}}=10$ (ND) and $12(\mathrm{~T} 2 \mathrm{D}) ;{ }^{\mathrm{e}}=10$ (ND) and 10 (T2D); ${ }^{\mathrm{f}}=10$ (ND) and 13 (T2D); ${ }^{\mathrm{g}}=13$ (ND) and 6 (T2D). 
Table 2. Physiological responses to the ramp incremental test.

\begin{tabular}{|c|c|c|c|}
\hline & ND & $\mathrm{T} 2 \mathrm{D}$ & $P$ value \\
\hline$n$ & 17 & 17 & \\
\hline$\dot{\mathrm{V}} \mathrm{O}_{2 \text { peak }}\left(\mathrm{mL} \cdot \mathrm{kg}^{-1} \cdot \mathrm{min}^{-1}\right)$ & $28.62 \pm 5.50^{*}$ & $22.48 \pm 3.65$ & $<0.001$ \\
\hline$\dot{\mathrm{V}} \mathrm{O}_{2 \text { peak }}\left(\mathrm{L} \cdot \mathrm{min}^{-1}\right)$ & $2.60 \pm 0.58^{*}$ & $2.18 \pm 0.65$ & 0.03 \\
\hline Peak PO $(W)$ & $196(108)^{*}$ & $186(106)$ & 0.04 \\
\hline Peak HR (beats.min ${ }^{-1}$ ) & $175(27)^{*}$ & $165(26)$ & 0.04 \\
\hline Peak RER (a.u.) & $1.2(0.1)$ & $1.1(0.1)$ & 0.20 \\
\hline Peak MAP $(\mathrm{mmHg})^{\mathrm{a}}$ & $126 \pm 17$ & $137 \pm 24$ & 0.14 \\
\hline Peak SBP $(\mathrm{mmHg})^{\mathrm{a}}$ & $170 \pm 24 *$ & $187 \pm 19$ & 0.05 \\
\hline Peak DBP $(\mathrm{mmHg})^{\mathrm{a}}$ & $103 \pm 16$ & $103 \pm 23$ & 0.48 \\
\hline$\dot{\mathrm{VO}} \mathrm{O}_{2}$ at $\mathrm{VT}(\mathrm{W})$ & $1.78 \pm 44^{*}$ & $1.55 \pm 0.47$ & 0.02 \\
\hline$\dot{\mathrm{V}} \mathrm{O}_{2}$ at $\mathrm{RCP}(\mathrm{W})$ & $2.25 \pm 0.49^{*}$ & $1.93 \pm 0.57$ & 0.04 \\
\hline
\end{tabular}

642 Mean \pm SD values are shown in normal font for variables which were normally distributed; 643 whereas median (and interquartile range) values are shown in italic font for variables which 644 showed significant skewness and were not normally distributed in one or both groups. $\dot{\mathrm{VO}}_{2}$, 645 volume of oxygen uptake; PO, power output; HR, heart rate; RER, respiratory exchange ratio; 646 MAP, mean arterial pressure; SBP, systolic blood pressure; DBP, diastolic blood pressure; VT, 647 ventilatory threshold; RCP, respiratory compensation point. Some variables have missing 648 values and the sample sizes with codes are shown below. *Significantly different than T2D $(P$ $649 \leq 0.05)$.

$650{ }^{\mathrm{a}}=9(\mathrm{ND})$ and $12(\mathrm{~T} 2 \mathrm{D})$.

651 
Table 3. Parameter estimates for the $\% \Delta[H H b+M b]$ profile for both groups plotted as a function of normalised $P O(\%)$ during the ramp incremental test.

655

\begin{tabular}{|l|c|c|c|}
\hline & ND & T2D & $P$ value \\
\hline$n$ & 14 & 14 & \\
\hline$b\left(\right.$ slope $\left._{1}\right)$ & $1.35(0.43)^{*}$ & $1.81(0.61)$ & 0.02 \\
\hline$b-c\left(\right.$ slope $\left._{2}\right)$ & $0.15 \pm 0.67$ & $-0.21 \pm 0.57$ & 0.14 \\
\hline$B P(\%)$ & $81.2 \pm 11.9$ & $75.2 \pm 12.5$ & 0.20 \\
\hline
\end{tabular}

656

657

658

Mean \pm SD values are shown in normal font for variables which were normally distributed;

659 whereas median (and interquartile range) values are shown in italic font for variables which

660 showed significant skewness and were not normally distributed in one or both groups. Slope 1

661

662 and Slope 2 of linear regression before and after breakpoint $(B P)$ respectively. ${ }^{*}$ Significantly different than T2D $(P<0.05)$.

663

664

665 